\title{
Peroxisome dynamics during development of the fungus Podospora anserina
}

\author{
Harumi Takano-Rojas \\ Departamento de Bioquímica y Biología Estructural, Instituto \\ de Fisiología Celular, Universidad Nacional Autónoma \\ de México, 04510, México DF, Mexico \\ Denise Zickler \\ Univ. Paris-Sud, CNRS UMR8621, Institut de Génétique \\ et Microbiologie, 91405 Orsay, France \\ Leonardo Peraza-Reyes ${ }^{1}$ \\ Departamento de Bioquímica y Biología Estructural, Instituto \\ de Fisiología Celular, Universidad Nacional Autónoma de \\ México, 04510, México DF, Mexico
}

\begin{abstract}
Peroxisomes are versatile and dynamic organelles that are required for the development of diverse eukaryotic organisms. We demonstrated previously that in the fungus Podospora anserina different peroxisomal functions are required at distinct stages of sexual development, including the initiation and progression of meiocyte (ascus) development and the differentiation and germination of sexual spores (ascospores). Peroxisome assembly during these processes relies on the differential activity of the protein machinery that drives the import of proteins into the organelle, indicating a complex developmental regulation of peroxisome formation and activity. Here we demonstrate that peroxisome dynamics is also highly regulated during development. We show that peroxisomes in $P$. anserina are highly dynamic and respond to metabolic and environmental cues by undergoing changes in size, morphology and number. In addition, peroxisomes of vegetative and sexual cell types are structurally different. During sexual development peroxisome number increases at two stages: at early ascus differentiation and during ascospore formation. These processes are accompanied by changes in peroxisome structure and distribution, which include a cell-polarized concentration of peroxisomes at the beginning of ascus development, as well as a morphological transition from predominantly spherical to elongated shapes at the end of the first meiotic division. Further, the mostly tubular peroxisomes present from second meiotic division to early ascospore formation again become rounded during ascospore differentiation. Ultimately the number of peroxisomes dramatically decreases upon ascospore maturation. Our results reveal a precise regulation of peroxisome dynamics during sexual development and suggest that
\end{abstract}

peroxisome constitution and function during development is defined by the coordinated regulation of the proteins that control peroxisome assembly and dynamics.

Key words: cell differentiation, fungi, meiosis, peroxisome dynamics, sexual development

\section{INTRODUCTION}

Peroxisomes are ubiquitous single membrane-bounded organelles that perform important metabolic functions. Throughout Eukaryota they play a major role in lipid metabolism (Lodhi and Semenkovich 2014). Peroxisomes compartmentalize numerous enzymes involved in the oxidative metabolism of distinct metabolites, including lipids, carbohydrates, amino acids and purines, which produce reactive oxygen species (ROS). They also contain various antioxidant enzymes and therefore have an active role in regulating ROS in the cell (Wanders and Waterham 2006, Nordgren and Fransen 2013, Sandalio et al. 2013). In addition, peroxisomes are versatile organelles performing specific metabolic activities that vary among organisms or even among tissues of a single organism (Gabaldon 2010). Furthermore, peroxisomes also are implicated in cell-signaling processes where they participate in the formation of signaling molecules (Corpas et al. 2013, León 2013, Spiess and Zolman 2013, Lodhi and Semenkovich 2014) or provide a subcellular platform that orchestrate complex signaling pathways (Dixit et al. 2010, Zhang et al. 2013).

Fungi provide a nice illustration of the functional versatility of peroxisomes (Maruyama and Kitamoto 2013, Stehlik et al. 2014). Throughout evolution peroxisomes have provided a wide spectrum of metabolic activities to fungal cells by the acquisition of enzymes involved in methanol assimilation (van der Klei et al. 2006), biosynthesis of biotin (Tanabe et al. 2011), siderophores (Grundlinger et al. 2013) and secondary metabolites such as extracellular glycolipids (Freitag et al. 2014), $\beta$-lactams (penicillin, cephalosporin) and mycotoxins (AK-toxin, paxilline) (Bartoszewska et al. 2011). Moreover, enzymes of the glyoxylate cycle (Kunze et al. 2006), the pentose phosphate pathway (Strijbis et al. 2012) and glycolysis (Freitag et al. 2012) localize to peroxisomes. The functional diversification of peroxisomes in fungi also includes the differentiation of distinct peroxisomal subcompartments, such as the Woronin bodies that temporally seal the septal pores that allow communication between hyphal compartments in filamentous ascomycetes (Jedd 2011). 
While diverse in function, peroxisomes share a common biogenetic process, which is mediated by conserved proteins known as peroxins. Peroxisome formation can be divided in three processes: i. peroxisome membrane protein import, ii. peroxisome matrix protein import and iii. peroxisome division and proliferation (Schrader et al. 2012, Kim and Hettema 2015). The import of proteins into the peroxisome matrix depends on two conserved import pathways (for a recent review see Kim and Hettema 2015). Each pathway is mediated by a specific import receptor, Pex5 or Pex7, which recognize their targets in the cytosol by means of their peroxisome-targeting sequence PTS1 and PTS2, respectively. The import receptors then drive protein import into the peroxisome and are recycled back to the cytosol to be used in further rounds of import. Pex7 additionally requires the activity of auxiliary proteins known as PTS2 co-receptors such as Pex20 in most fungi (Kiel et al. 2006). Both import pathways converge at the docking/translocation machinery, which is composed by the peroxisome membrane proteins Pex13, Pex14 and in filamentous ascomycetes by Pex14/17(Pex33) (Kiel et al. 2006, Managadze et al. 2010, Opalinski et al. 2010). It is important to note that the import receptor Pex5 and the docking peroxin Pex14 compose the PTS1 protein import channel in Saccharomyces cerevisiae (Meinecke et al. 2010). The docking complex interacts with a second peroxisome membrane complex, the RING finger complex, that is composed of the E3 ubiquitin ligases Pex2, Pex10 and Pex12. The RING finger complex, along with the E2 ubiquitin conjugating-enzyme complex Pex4/Pex22, ubiquitinates the import receptor to promote its further release from the membrane by the Pex1/Pex6 AAA ATPase complex (Platta et al. 2014).

Consistent with their functional versatility, peroxisomes are essential for the development of many eukaryotic organisms. In fungi many developmental processes of sexual reproduction depend on peroxisomes (reviewed in Peraza-Reyes and Berteaux-Lecellier 2013). Our research on the filamentous ascomycete Podospora anserina has shown that peroxisomes are indispensable during stages of its sexual development. Distinct peroxisomal functions are required for the induction and progression of meiocyte (ascus) development, as well as for the subsequent formation and germination of the meiotic-derived sexual spores (ascospores) (Berteaux-Lecellier et al. 1995, Bonnet et al. 2006, Peraza-Reyes et al. 2008, Boisnard et al. 2009). We have discovered that the functional state of the docking/translocation machinery changes during the sexual cycle and we have provided evidence that an alternative peroxisome matrix import cycle is involved in defining peroxisome function during sexual development (Peraza-Reyes et al. 2011). However, the mechanisms responsible for peroxisome regulation during development remain poorly understood. Therefore to better comprehend the developmental regulation of this organelle, we performed detailed cytological analyses of peroxisome morphogenesis and dynamics during the vegetative and sexual cycles of $P$. anserina. Our analysis provides a coherent view of peroxisome dynamics through development, in correlation with the functional state of the proteins controlling peroxisome assembly.

\section{MATERIALS AND METHODS}

Strains and culture conditions. - The strains of P. anserina used for this research were derived from the $S$ genetic background. $P$. anserina was grown at $27 \mathrm{C}$ on M2 minimal medium containing either $1.1 \%$ dextrin or $0.05 \%$ oleic acid (with $0.2 \%$ tween 40 as emulsifier) as sole carbon sources. Ascospores were germinated on G medium (Rizet and Engelmann 1949). Current methods can be found at http:/ / podospora.igmors.u-psud.fr/methods.php

Cytology and fluorescence microscopy.-Peroxisomes were visualized with peroxisome-targeted GFP containing the canonical PTS1 C-terminal Ser-Lys-Leu tripeptide (RuprichRobert et al. 2002). FOX2 was detected with antibodies raised against synthetic peptides from $P$. anserina FOX2 (Eurogentec, Angers, France). Mitochondrial and nuclear DNA were stained with DAPI $\left(0.5 \mathrm{mg} \mathrm{mL}^{-1}\right)$. Cells were fixed in $7.4 \%$ paraformaldehyde and processed for fluorescence microscopy as described in Thompson-Coffe and Zickler (1994). Live-cell imaging was done by the inverted agar block method (Hickey et al. 2002) adapted for P. anserina. Briefly thin agar blocks (5 $\mathrm{mm}$ deep) containing whole individual $P$. anserina colonies $(\approx 1 \mathrm{~cm}$ diam $)$ grown $24 \mathrm{~h}$ on M2 agar plates were transferred to microscope slides and observed under a glass cover slip. For quantification of peroxisomal velocity, cells were imaged at $0.38-3 \mathrm{~s}$ (fast time-lapse imaging) or $20 \mathrm{~s}$ (slow imaging) intervals by confocal microscopy (see below). Velocities were calculated by determining the change in position of a peroxisome as a function of time, for at least five consecutive frames. Transmitted-light images of the growing hyphae were collected to determine hyphal growth rate. Imaging was performed on one of the following microscope systems: Zeiss Axioplan with a Princeton CDD camera, Leica DMIRE2 with a Roper Scientific CDD camera, Nikon Eclipse E600 with a Neo Andor sCMOS camera or on a Zeiss LSM710 laser scanning confocal microscope with a $488 \mathrm{~nm}$ laser line. Maximum-intensity projections were obtained from $\mathrm{z}$ series of images collected at $0.2 \mu \mathrm{m}$ intervals. Images were processed with ZEN 2012 (Zeiss) or ImageJ (NIH, Bethesda, Maryland) software.

\section{RESULTS}

Peroxisomes are highly dynamic organelles during the vegetative cycle.-Peroxisome shape, distribution and movements were analyzed in vegetative hyphae on 


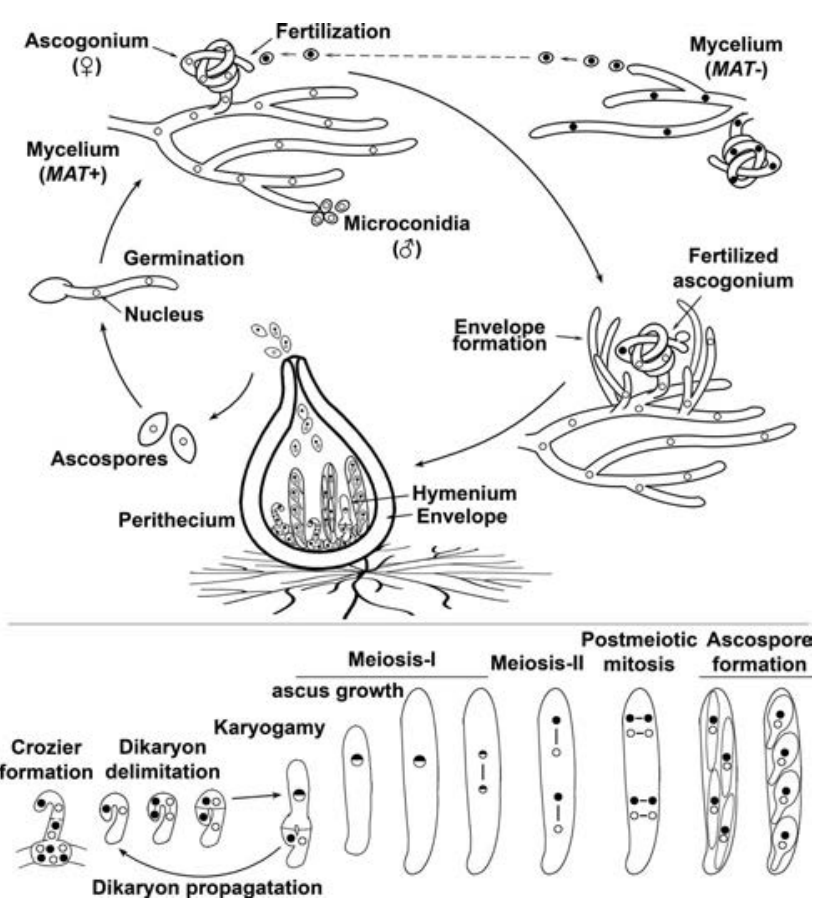

FIG. 1. The life cycle of $P$. anserina. Upper: $P$. anserina is a heterothalic fungus that possesses two mating-types (mat+ and mat-). Strains of each mating-type differentiate both female gametangia (ascogonia) and male gametes (microconidia), but mating occurs only between sexual structures of opposite mating-type. The ascogonium emerges from vegetative hyphae as a single multinucleated coiled hyphal branch. Each ascogonium recruits surrounding hyphae to produce a protective envelope and creates the protoperithecium, which after fertilization develops into a perithecium. $P$. anserina differentiates uninucleated single cells (microconidia) that are unable to germinate but function as male gametes. During fertilization their nuclei migrate into the ascogonium, which contains female nuclei. This results in the formation of the hymenium, where karyogamy, meiosis and sexual spore (ascospore) formation take place. After maturation ascospores are forcibly expelled from the perithecium. Lower: Sexual development from the dikaryotic stage to ascospore formation (from left to right). After fertilization the female and male nuclei present in ascogonial cells are segregated in pairs in specialized hook-shaped ascogenous hyphae called croziers. In these cells coordinated mitoses and septa formation separate an upper binucleated cell (with opposite mating-type nuclei) from two lower uninucleated cells. The upper dikaryotic cell differentiates into an ascus (meiocyte), whereas the two uninucleated cells fuse to produce a new crozier. Karyogamy, meiosis and a succeeding mitosis take place in the ascus to yield eight haploid nuclei, which are packaged by pairs into four dikaryotic ascospores that mature inside the original mother ascus.

standard dextrin-containing medium, using a peroxisome matrix-targeted GFP (GFP-PTS1; $P$. anserina life cycle is described (FIG. 1). Live-cell time-lapse fluorescence microscopy revealed two main classes of GFP-PTS1-stained peroxisomes, according to their size and morphology. The first class consisted in round punctate structures, $0.43-1.31 \mu \mathrm{m}$ in diam (av. $0.75 \pm$ $0.16 \mu \mathrm{m}, n=90$ ) (Fig. 2A, Supplementary VIDEO 1), while the second class was characterized by flexible elongated peroxisomes, which were more variable in size (SUPPLEMENTARY VIDEO 2 and below). Hyphae from standard growth conditions contained predominantly spherical peroxisomes (FIG. 2A).

Two classes of peroxisomes also were observed when their motility was compared. The vast majority of peroxisomes move forward, toward the extending apex of the growing hyphae, with a relatively low velocity (SUPPLEMENTARY VIDEO 1). The displacement of these peroxisomes was relatively constant. Moreover, their overall velocity ( $39 \pm 21 \mathrm{~nm} / \mathrm{s}, n=65)$ correlated with the hyphal elongation rate $(35 \mathrm{~nm} / \mathrm{s})$, suggesting that their movement was propelled by the cytoplasmic bulk flow. In addition, these peroxisomes exhibited short-range constrained saltatory movements. Fast time-lapse imaging revealed that these movements occurred with an average velocity of $222.81 \pm 104.14 \mathrm{~nm} / \mathrm{s}(n=90)$.

The second class of peroxisomes was engaged in fast long-distance movements, which predominantly occurred along the longitudinal hyphal axis. These movements occurred in both directions: toward (anterograde) and backward (retrograde) from the
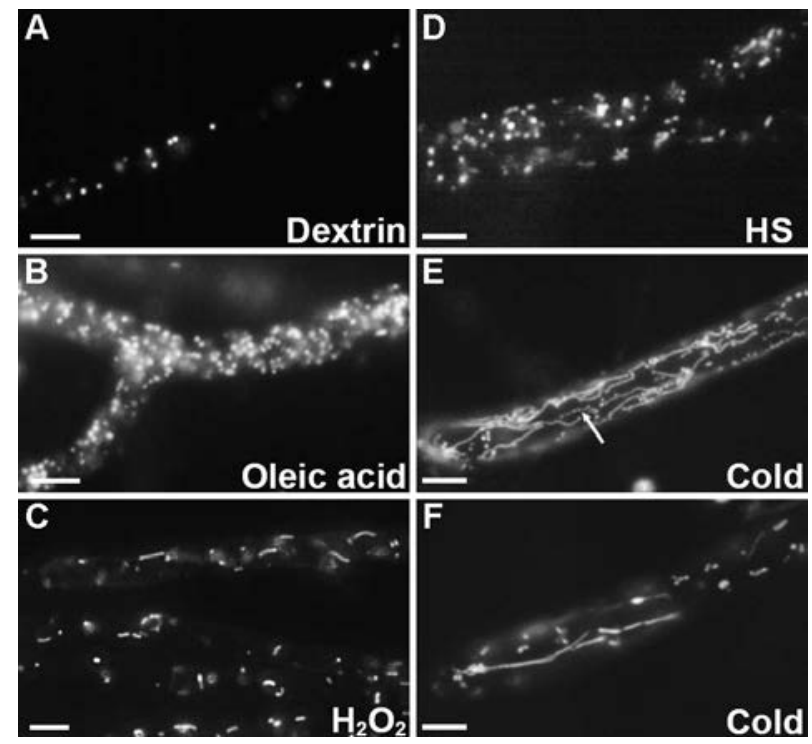

FIG. 2. Hyphal peroxisomes. Peroxisomes were visualized with peroxisome-targeted GFP (GFP-PTS1) in hyphae on minimal medium containing dextrin (A) or oleic acid (B) as sole carbon sources. Dextrin-growing hyphae were exposed to $50 \mathrm{mM} \mathrm{H} \mathrm{O}_{2}$ and imaged after $5 \mathrm{~min}(\mathrm{C})$ or were exposed to $37 \mathrm{C}$ for $1 \mathrm{~h}(\mathrm{D})$ or to low temperature $(4 \mathrm{C})$ for $12 \mathrm{~h}(\mathrm{E}$, F). Arrow points to peroxisomes with a "beads on a string" arrangement. Bars $=5 \mu \mathrm{m}$. 
hyphal apex, and they were similar both in distance and velocity. Anterograde movements occurred within 4.81-26.43 $\mu \mathrm{m}$ (av. $9.83 \pm 6.25 \mu \mathrm{m}, n=61$ ), whereas retrograde ones occurred in $5.36-17.46 \mu \mathrm{m}$ (av. $9.41 \pm 3.52 \mu \mathrm{m}, n=54$ ). The average velocity of anterograde displacements was $1.57 \pm 0.34 \mu \mathrm{m} / \mathrm{s}$, while that of retrograde movements was $1.41 \pm 0.49 \mu \mathrm{m} / \mathrm{s}$. Overall the frequency of anterograde $(50.98 \%)$ and retrograde $(49.01 \%)$ displacements was similar, and frequently (in $70.58 \%$ of all recorded moving peroxisomes) the same peroxisome was engaged in sequential anterograde and retrograde movements (e.g. the bright peroxisome in SUPPLEMENTARY VIDEO 2 but see also Supplementary VIDEO 4 for more examples).

The presence of elongated peroxisomes could reflect the process of peroxisome division, in which peroxisomes elongate and undergo fission to produce new peroxisomes. Actually we observed that some cells contained clusters of longitudinally aligned round peroxisomes with a "beads on a string" arrangement, which likely resulted from the fission of elongated peroxisomes. We observed peroxisome fission in $P$. anserina commencing by the appearance of a peroxisomal protrusion, which further extends and divides rapidly into several new peroxisomes (SUPPLEMENTARY VIDEO 3, arrow). Overall this process took place in about $14 \mathrm{~min}$. Of note the beaded clusters of aligned peroxisomes often moved jointly along the cell (SUPPLEMENTARY VIDEO 4), suggesting that they represent constricted peroxisomes or newly formed round peroxisomes that remain connected.

To further appreciate the process of peroxisome division and proliferation, we also tested whether oleic acid, a well-known inductor of peroxisome proliferation in fungi, was able to enhance peroxisome proliferation in $P$. anserina. As expected we observed a dramatic increase in the number of hyphal peroxisomes when $P$. anserina grew on medium containing oleic acid as sole carbon source (FIG. 2B, cf. 2A).

Elongated peroxisomes in animal and plant cells have been associated with specific physiological conditions, such as oxidative stress (Schrader et al. 1999, Sinclair et al. 2009). Similarly we observed elongation of peroxisomes under oxidative stress. Treatment of dextrin-growing hyphae with $50 \mathrm{mM} \mathrm{H}_{2} \mathrm{O}_{2}$ induced a rapid elongation of peroxisomes, which started after 2 min of $\mathrm{H}_{2} \mathrm{O}_{2}$ exposure and was prominent after 5 min (FIG. 2C). Under these conditions elongation of peroxisomes was relatively uniform, av. $1.68 \pm$ $0.603 \mu \mathrm{m}$ long $(n=150)$.

In addition, we tested whether peroxisome dynamics also was affected by other stresses. Exposing cells to low temperature $(4 \mathrm{C})$ for $12 \mathrm{~h}$ resulted in extensive elongation of peroxisomes, with an increase of long-beaded

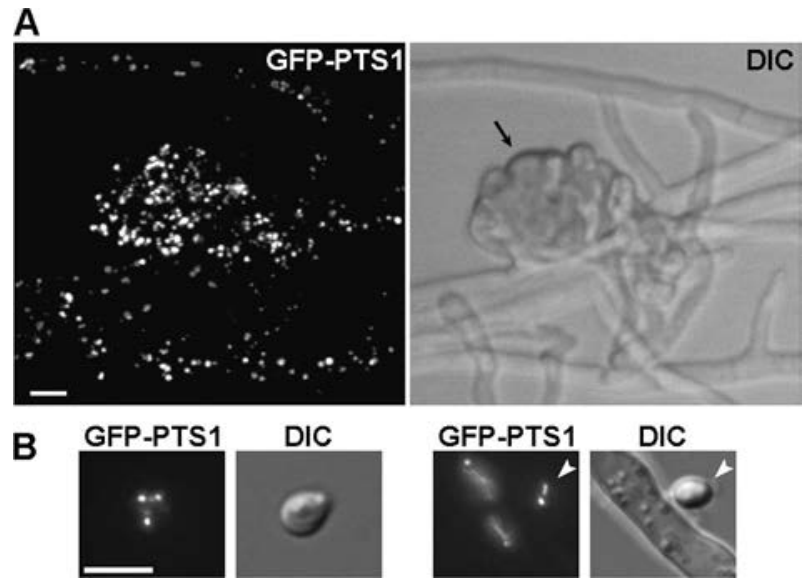

FIG. 3. Peroxisomes in ascogonia and microconidia. Maximum projections of an ascogonium (A, arrow) and microconidia (B) expressing peroxisome-targeted GFP (GFP-PTS1, left panels). Right panels: corresponding differential interference contrast (DIC) micrographs. Arrowheads in (B) point to a microconidium. Bars $=5 \mu \mathrm{m}$.

peroxisomes (FIG. 2E, arrow). Moreover, peroxisomes were much longer than without temperature shift or than those present under $\mathrm{H}_{2} \mathrm{O}_{2}$ exposure, reaching as much as $8.05 \mu \mathrm{m}$ long (av. $2.86 \pm 1.5 \mu \mathrm{m}$ av., $n=$ 102) (FIG. 2E, F). Round peroxisomes, however, still were present. In contrast, exposing cells to high temperature $(37 \mathrm{C})$ for $30 \mathrm{~min}$ had only a moderate and transient effect on peroxisome elongation; however, an increase in the number of peroxisomes was observed after longer exposure (1 h) (FIG. 2D).

Peroxisome dynamics during the stages of the $\mathrm{P}$. anserina sexual cycle.-This cycle can be conveniently divided into five distinct stages of development (FIG. 1).

Ascogonia and microconidia.-Sexual development begins with the differentiation of female gametangia (ascogonia) and male gametes (microconidia). The ascogonium originates as a multinucleated hyphal branch that emerges from vegetative hypha and coils as either left- or right-handed helices. Analysis of ascogonia by confocal microscopy showed the presence of numerous peroxisomes that were predominantly spherical but with different sizes and fluorescent intensity (Fig. 3A, Supplementary VIDEO 5). These peroxisomes were morphologically similar to those present in vegetative hyphae. Microconida arise from short, aerial branches also emerging from vegetative hyphae. These uninucleated cells contain small amounts of cytoplasm and few small peroxisomes (1-6 per cell, av. $=2.7, n=93$ ), which are either spherical or slightly elongated (FIG. 3B). Peroxisomes were present in 91\% of the analyzed microconidia $(n=188)$, but $9 \%$ had no peroxisomes. Some microconidia had beaded 

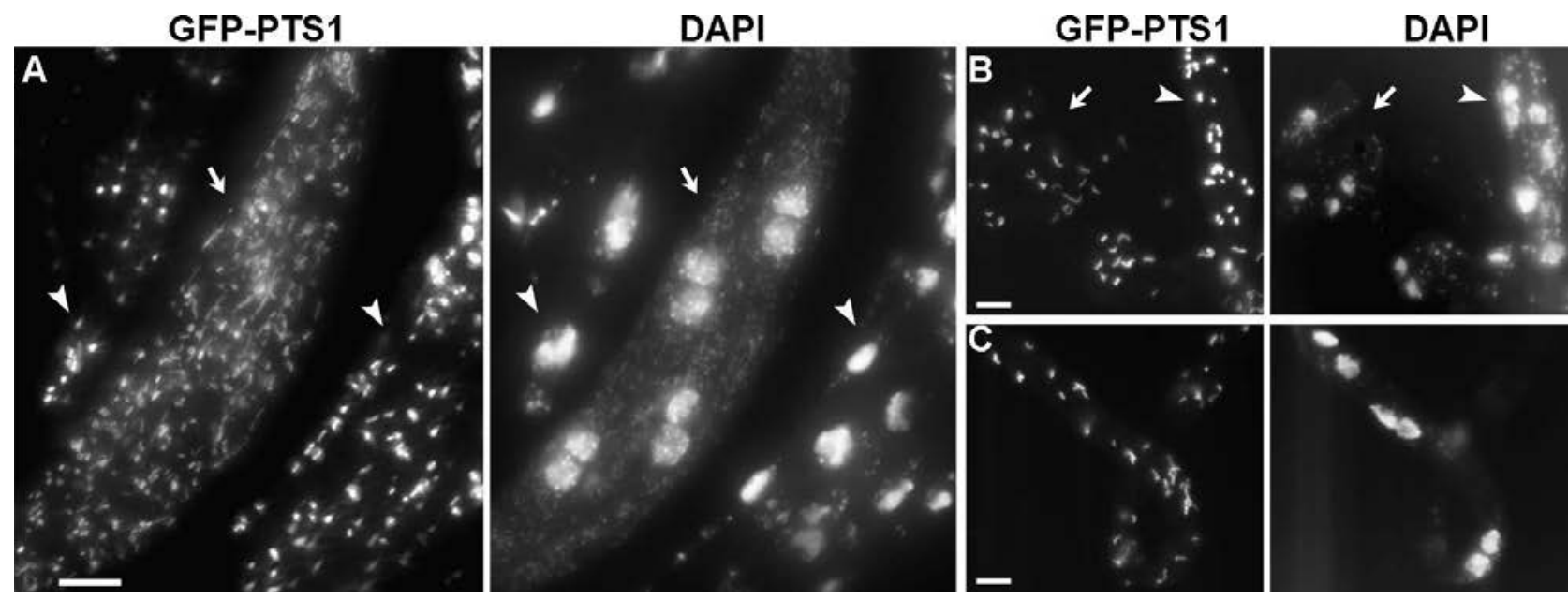

FIG. 4. Peroxisomes in the sexual and asexual cell lineages of perithecia. A. Maximum projections showing the morphology of GFP-PTS1-stained peroxisomes (left panel) present in an ascus containing four young early-differentiated ascospores (arrow) and in surrounding multinucleated paraphyses (arrowheads); right panel: corresponding DAPI (note the presence of two nuclei inside each ascospore). B, C, left panels. Peroxisome morphology in perithecia ascogonial cells (B arrow), and in large (B arrowhead) and slender $(\mathrm{C})$ paraphysal cells; right panel: corresponding DAPI. Bars $=5 \mu \mathrm{m}$.

peroxisome chains (FIG. 3B arrow), suggesting that peroxisomes can divide within these highly specialized cells.

The sexual and asexual cells of perithecia contain distinct types of peroxisomes.-Upon migration of the "male" nuclei into the ascogonium, this latter is enveloped by highly interwoven hyphae, which will form the flask-shaped perithecium. Inside the perithecium male and female nuclei divide within the coenocytic female structure before individualization of dikaryotic crozier cells. After nuclear fusion (karyogamy) cells grow into asci, where meiosis will take place followed by a post-meiotic division and ascospore formation (FIG. 1). In addition to asci (FIG. 4 arrow) the perithecium also contains plurinucleated specialized sterile hyphae (paraphyses, Fig. 4 arrowheads), which are interspersed between asci and are exclusively of maternal origin. Peroxisomes present in paraphyses are either spherical or tubular (shown in Fig. 4 for two different paraphyseal cells B, C). However, of interest they are structurally different from those seen in asci and ascospores (FIG. 4A). Notably peroxisomes present in paraphyses are larger and brighter than those present in asci. For example, elongated peroxisomes present in paraphyses were av. $0.5 \pm 0.08 \mu \mathrm{m}$ wide $(n=102)$, compared to $0.32 \pm 0.05 \mu \mathrm{m}(n=100)$ in asci with young differentiated ascospores (FIG. 4A). Peroxisomes of paraphyses also are much brighter than those present in the ascogonial cells (FIG. 4B).

Changes in peroxisome composition during dikaryotic cell differentiation.-Peroxisomes present in the dikaryotic crozier cells are almost exclusively round (FIG. 5A, $a$ and $b$ ). Only $77 \%$ of croziers show detectable peroxisomes (Peraza-Reyes et al. 2011), which furthermore, are smaller and less bright than in other cell types. However, an increase in peroxisome fluorescence was noticeable when these cells underwent karyogamy (FIG. 5A $c$, cf. $a$ and $b$ ). Likewise peroxisomes of comparable brightness were noticeable at the basal cells (the reminiscent croziers) of young asci (see FIG. 5A ascus $d$ ). As these peroxisomes are stained by antibodies against endogenous FOX2 - the peroxisome fatty acid $\beta$-oxidation multifunctional protein 2 - the change in brightness likely indicate a change in the composition or import competency of peroxisomes just before ascus development.

Peroxisome number, shape and distribution change during ascus development.-After karyogamy the crozier upper cell differentiates into an ascus, which elongates from about 10 to more than 150 microns during the first meiotic prophase (FIG. 5, compare asci from Ad, B and $\mathrm{C}$ ). Observations have revealed that during ascus growth peroxisomes increase in number and group at the apex of the elongating cells (Berteaux-Lecellier et al. 1995). Detailed analysis of the different steps of ascus growth indicated that, in 33 analyzed asci, $70 \%$ of the young asci $(12-40 \mu \mathrm{m}$ long) showed indeed a high concentration of peroxisomes at their apex (arrowhead in FIG. 5B). When asci elongated to $88 \mu \mathrm{m}$, peroxisomes continued to increase in number but only $40 \%$ showed a prominent concentration at their apex. When asci reached $150 \mu$ (Figs. 5C, 6A), peroxisomes distributed more evenly along the cell.

Of interest, closer inspection of peroxisome morphology during ascus development revealed a second change in peroxisome dynamics. Asci of first 

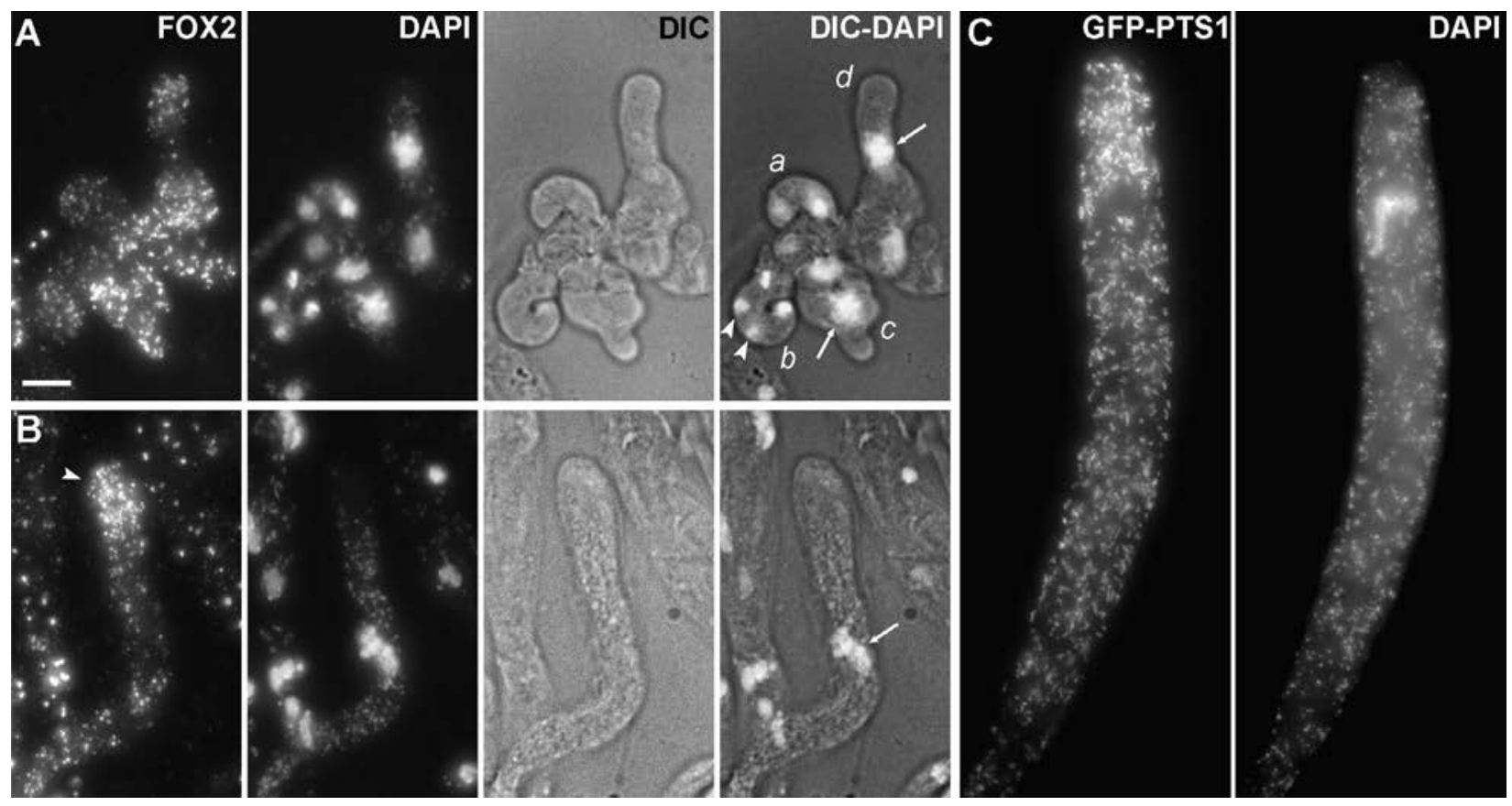

FIG. 5. Peroxisomes from the dikaryotic crozier stage to first meiotic prophase. A,B. From left to right: peroxisomes stained with anti-FOX2 antibody (FOX2), nuclei stained with DAPI, differential interference contrast (DIC) micrographs and DAPImerged DIC images (DIC-DAPI). Small letters in A (right) indicate successive developmental stages from crozier ( $a$ and $b$ ) to karyogamy $(c)$ and ascus formation $(d)$ : $(a)$ binucleated young crozier bending. (b) Simultaneous mitosis in crozier results in four nuclei (arrowheads indicate the nuclei that will be engaged in karyogamy). (c) Karyogamy (arrows point to the diploid nucleus). ( $d$ ) Upon karyogamy the crozier upper cell elongates to produce the ascus, which further elongates during meiotic prophase I. B. Ascus in early meiotic prophase with peroxisomes concentrated at the ascus tip (arrowhead). C. Left panel: GFPstained peroxisomes redistribute during first meiotic prophase in parallel with ascus elongation; right panel: corresponding DAPI. Images show maximum-intensity projections of $\mathrm{z}$ series through the entire cells. Bar $=5 \mu \mathrm{m}$.

meiotic division harbor predominantly round peroxisomes (FIG. 6A, B). In contrast, by the end of the first meiotic division peroxisomes tend to be more elongated (FIG. 6C). This pattern of elongated peroxisomes is maintained during the second meiotic division (FIG. 6D), the post-meiotic mitosis (FIG. 6E) and in the newly differentiated ascospores (FIG. 4A).

Peroxisome number and shape change again during ascospore differentiation.-A second proliferation of peroxisomes occurs after ascospore delimitation (Berteaux-Lecellier et al. 1995). This dramatic increase in peroxisomes is illustrated (FIG. 7). Notably peroxisome morphology also changes in this process. Young ascospores contain predominantly elongated peroxisomes (FIG. 7A, see also FIG. 4A for earlier ascosporedifferentiation stage). Ascospores then differentiate a large head and a slender tail (FIG. 7B-D), and their initial volume increases approximately 10 times (Raju and Perkins 1994). Subsequently a septum forms at the head-tail junction and the tail cell ultimately degenerates (FIG. 7E). Of interest, we observed that the increase in peroxisome number that occurs during ascospore differentiation is also accompanied by a transition in peroxisome morphology, from mostly elongated (FIG. 7A, B) to predominantly spherical peroxisomes (FIG. 7D, E). This phenomenon was suggested by labeling peroxisomes with PEX2-GFP (a peroxisome membrane protein) and anti-FOX2 antibodies (Peraza-Reyes et al. 2008).

Peroxisome number dramatically decreases after ascospore maturation.-During the maturation process ascospores continue to grow and are pigmented by melanization of their cell walls, yielding black mature ascospores. Along with this process the meiotic-derived haploid nuclei divide several times leading to multinucleated ascospores (compare DAPI of FIG. 8A, B). Of note the large number of peroxisomes present in tailed ascospores (FIG. 7) dramatically decreases during maturation (FIG. 8). Peroxisomes were numerous in large tailless ascospores before nuclear proliferation; however, in contrast to previous stages these peroxisomes tend to aggregate (FIG. 8A). Subsequently peroxisome number decreases significantly leading to multinucleated mature ascospores possessing few spherical peroxisomes aligned in chains (FIG. 8B-D).

Ascospore peroxisomes are displaced into germinative cells upon germination.-Analysis of ascospore germination revealed that peroxisomes are present in the 

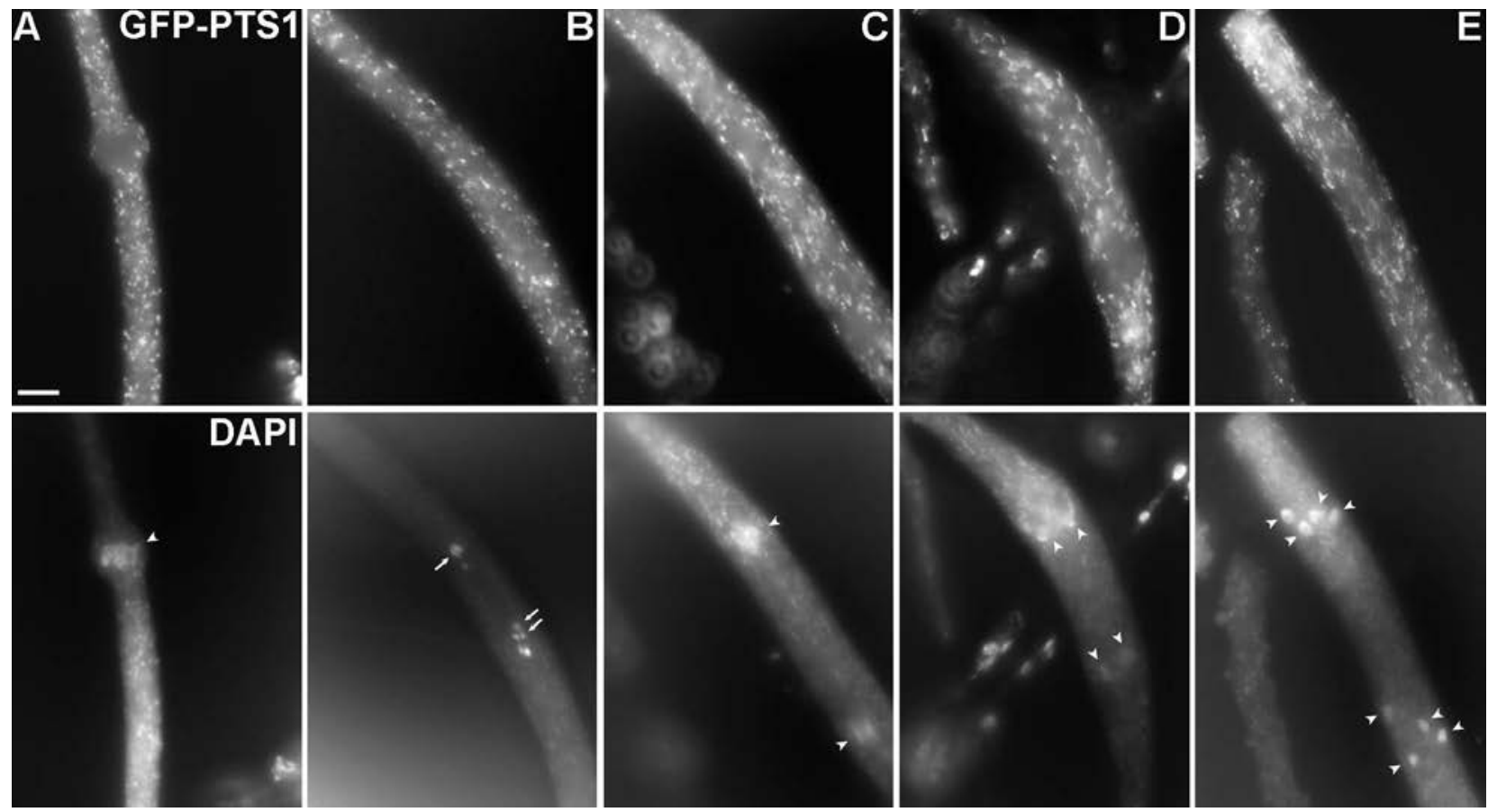

FIG. 6. Peroxisome morphology changes during ascus development. A-E, upper panels: morphology of GFP-PTS1-stained peroxisomes. Lower panels: corresponding DAPI. A. After ascus elongation, the first meiotic prophase nucleus migrates to the cell equator. B. Anaphase of the first meiotic division (the spindles are perpendicular; the seven chromosome pairs, arrows, are not in the focal plane of the DAPI image). After the first $(\mathrm{C})$ and second (D) meiotic divisions a post-meiotic mitosis results in the formation of eight nuclei inside each ascus (E arrowheads). Note how the predominantly spherical peroxisomes of the first meiotic prophase ascus (A) elongate by the end of the first meiotic division (C) and remain elongated until the post-meiotic mitosis (E). Arrowheads indicate nuclei. Bar $=5 \mu \mathrm{m}$.

germinative cells (the germination peg, see FIG. 9) as soon as they emerged from the ascospores (FIG. 9B). These peroxisomes further propagate along the growing hyphae and show similar morphologies to those seen in germinative pegs (FIG. 9B, compare to C, D) and in mycelial hyphae (FIG. 2A). Concomitant with the formation of the germination peg we observed that the ascospore cytoplasm, including peroxisomes, is displaced into the germination peg apparently by the formation of large vacuoles inside the ascospores (FIG. 9E). This suggests that during the initial germination stages the peroxisomes observed in the germinative cells are issued from the ascospore.

\section{DISCUSSION}

Peroxisomes are highly versatile organelles that provide functional versatility to the fungal cell. This versatility is reflected by the diverse development processes in which fungal peroxisomes have been implicated, including sexual development. Our research now demonstrates that peroxisomes are also highly regulated in shape, number and localization during the stages of both vegetative and the sexual development, as well as in response to the cell metabolic demands or to environmental stimuli. These findings provide evidence of an exquisite regulation of peroxisome dynamics during fungal development.

Fungal peroxisomes are highly dynamic organelles.Live-cell analyses of peroxisomes in vegetative cells revealed that most of them follow passively the cytoplasmic bulk flow that accompanies the hyphal expansion. However, a number of peroxisomes are able to surpass the cytoplasmic stream by engaging in fast long-distance displacements, which likely allows their repositioning in the hyphal cells. These peroxisomes move along the hypha in both directions with velocities similar to those reported for A. nidulans, where peroxisome displacements depend on the microtubule-based molecular motors dynein and kinesin-3/UncA (Egan et al. 2012). The presence of the corresponding ortho$\operatorname{logs}$ in the $P$. anserina genome suggests that both fungi likely use similar peroxisome transport systems.

Peroxisomes are regulated in response to metabolic and environmental cues.-Peroxisome proliferation in both single-celled (e.g. budding yeast, Veenhuis et al. 1987) and mycelial fungi (like A. nidulans, Valenciano et al. 1996) is enhanced by carbon sources such as fatty 

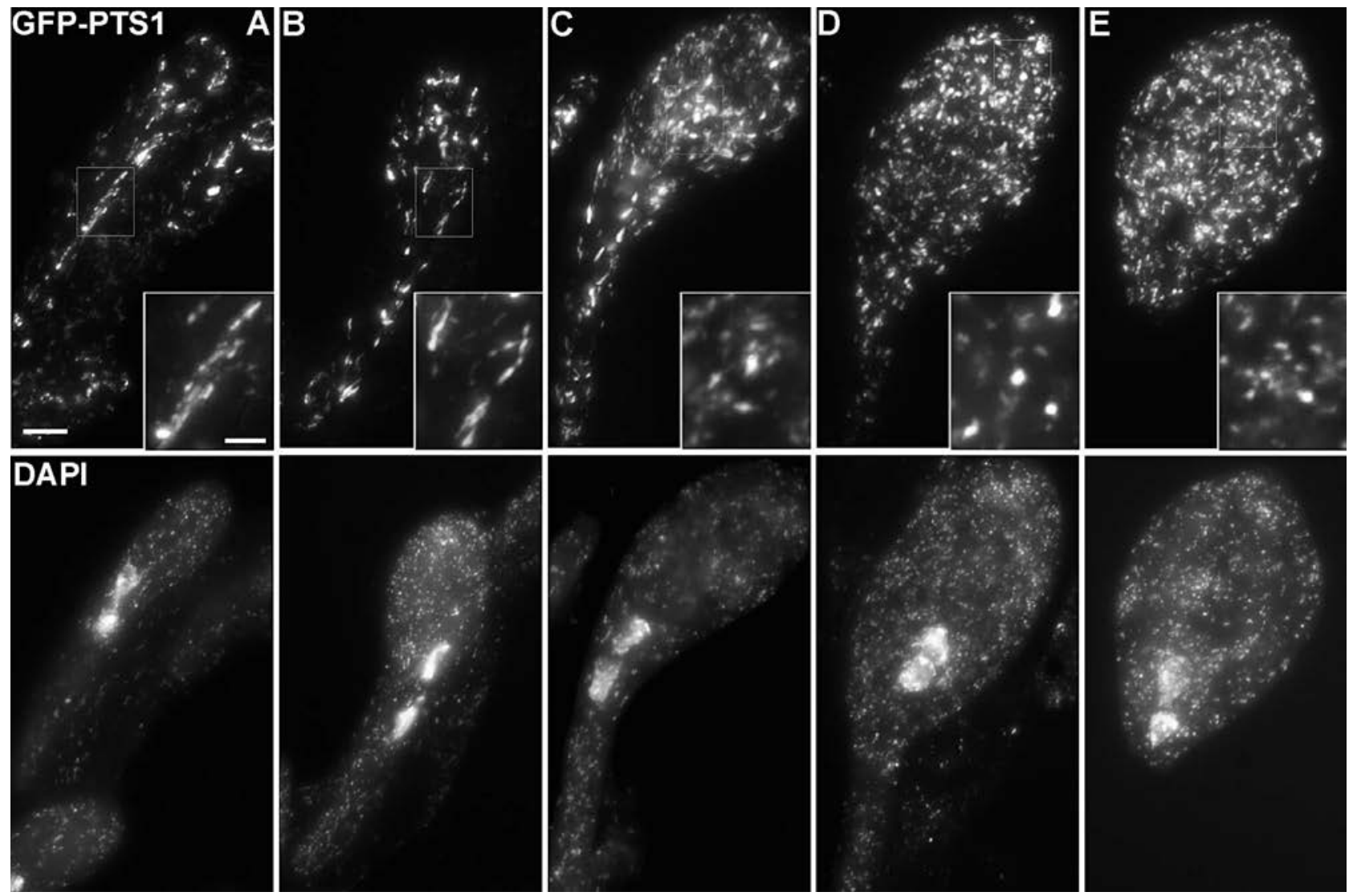

FIG. 7. Peroxisome shape and number change during ascospore differentiation. Upper panels: Maximum projections of GFPPTS1-stained peroxisomes. Insets correspond to magnifications of the areas indicated by gray squares (for clarity, magnifications in C-E correspond to z-series planes where peroxisomes of the selected areas are in focus). Lower panels: corresponding DAPI (note the presence of two nuclei per ascospore). A-D. The newly delineated elongated ascospores (A, see also FIG. 4A for an earlier developmental stage) grow asymmetrically adopting a tail shape (B-D). Ascospores then divide into head and tail cells, and the latter cell subsequently degenerates $(\mathrm{E})$. Note that peroxisome number increases along this process and that their shape changes progressively from mostly elongated to predominantly spherical (insets). Bar $=5 \mu \mathrm{m}$. Inset bar $=2 \mu \mathrm{m}$.

acids that require peroxisome metabolism. In P. anserina peroxisomes are required for medium- and longchain fatty acid utilization in a process that involves the $\beta$-oxidation pathway (Boisnard et al. 2009). Consistently we observed a dramatic proliferation of hyphal peroxisomes when $P$. anserina grew on oleic acidcontaining medium.

In addition to changes in number, we show that peroxisomes change shape from round to elongated in response to environmental stress. Various stress conditions that result in $\mathrm{H}_{2} \mathrm{O}_{2}$ formation also promote the elongation of peroxisomes both in plant and animal cells (Schrader et al. 1999, Sinclair et al. 2009). Peroxisomes have been suggested to act as cellular sensors of the redox and oxidative state of the cell (Sandalio et al. 2013). Actually the generation of oxidative stress within peroxisomes (Ivashchenko et al. 2011) or environmental conditions such as $\mathrm{H}_{2} \mathrm{O}_{2}$-produced oxidative stress and heat stress (Ayer et al. 2013) disturb the redox state of peroxisomes. Moreover, different stresses leading to $\mathrm{H}_{2} \mathrm{O}_{2}$ increase also induce peroxisome biogenesis genes (Lopez-Huertas et al. 2000), suggesting that the proliferation of peroxisomes could provide an antioxidant defense mechanism. Peroxisome elongation and proliferation under stress suggests that peroxisomes in $P$. anserina likely play a role in sensing alterations in the redox state and adapt their dynamics in response to specifically cope with physiological conditions.

Peroxisome dynamics are highly coordinated in a cell-dependent manner during the sexual cycle-Our research revealed that, in addition to the cell type-dependent proliferation of peroxisomes during the $P$. anserina sexual cycle, peroxisomes also change size, shape and distribution between the asexual and sexual cells in the multicellular fruiting body (perithecium) and during ascus and ascospore development. 

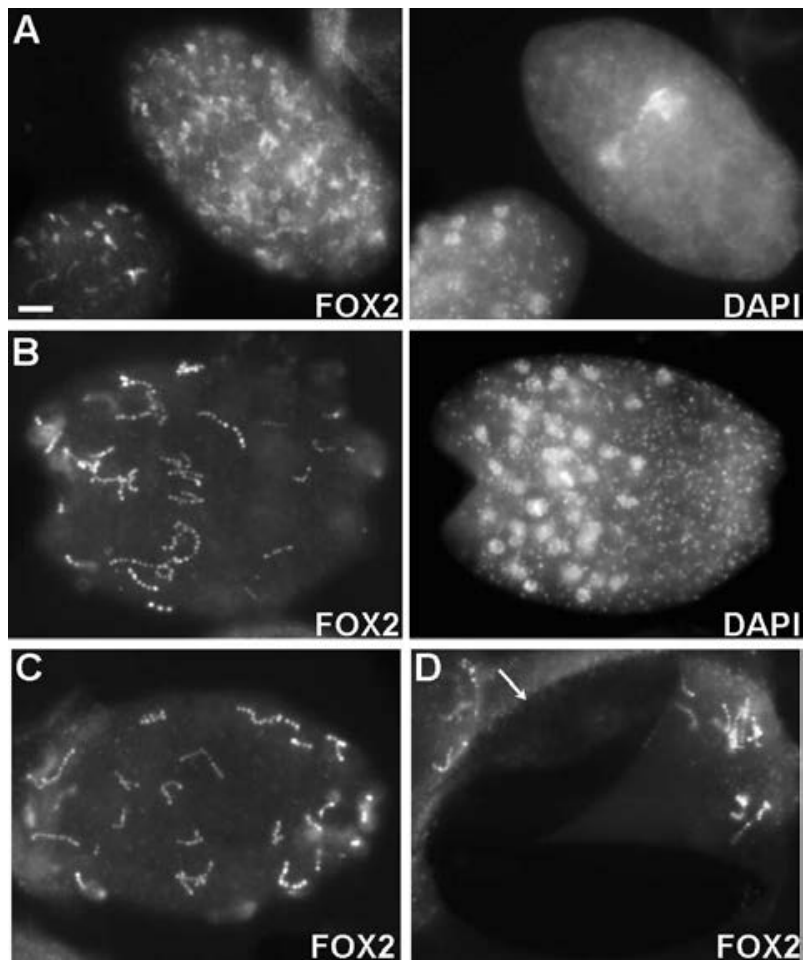

FIG. 8. Peroxisome number decreases after ascospore maturation. Peroxisomes were visualized with anti-FOX2 antibody (FOX2 panels), and nuclear and mitochondrial DNA were stained with DAPI (A, B, right panels). After loosing their tail the binucleated ascospores continue to grow (A, right spore) and undergo several nuclear divisions (A, left cell) to yield multinucleated ascospores, as seen in (B). During this process the ascospore cell wall is melanized, producing black-pigmented ascospores $(\mathrm{D}$, note the bivalvelike remaining spore envelope (arrow) of a ruptured ascospore). Note the dramatic reduction in peroxisomes along this process; ripe ascospores contain only few aligned peroxisomes. Bar $=5 \mu \mathrm{m}$.

First, within the perithecium peroxisomes present in vegetative (paraphyses) and sexual cells are structurally different. In paraphyses peroxisomes are noticeably larger and brighter than those of asci, suggesting that they could differ in composition and/or import competency. Also when elongated peroxisomes present in paraphyses were wider than in sexual cells (FIG. 4A), suggesting the induction of higher peroxisome membrane curvature in sexual cells. Furthermore, paraphysal peroxisomes are evenly distributed throughout the cell, in contrast to the peroxisomes of young asci, which tend to cluster at the cell tip. This indicates a differential modulation of the factors that control peroxisome shape and distribution in different cell types.

Also intriguingly dikaryotic crozier cells contain only few and small peroxisomes, and about one-third of them do not have detectable peroxisomes (PerazaReyes et al. 2011). Such paucity is surprising because peroxisomes are required for the differentiation of dikaryotic crozier cells into asci and for entry into meiosis (Berteaux-Lecellier et al. 1995, Peraza-Reyes et al. 2008, Peraza-Reyes et al. 2011). This observation, however, could be related to the fact that both peroxisomal proteins used here to visualize peroxisomes depend on PEX5 for import. In fact, we demonstrated that meiocyte formation does not depend on PEX5 or PEX7 (Bonnet et al. 2006) but requires a specific number of peroxins, which likely constitute an alternative peroxisome matrix protein import pathway in which PEX20 could provide the import receptor activity (Berteaux-Lecellier et al. 1995, Bonnet et al. 2006, PerazaReyes et al. 2008, Peraza-Reyes et al. 2011). Under this scenario scarceness of FOX2- and GFP-PTS1detectable peroxisomes in croziers would be consistent with a PEX5-independent alternative import pathway in those highly specialized cells. In addition, the crozier peroxisome fluorescence increase during karyogamy could be correlated to a change in peroxisome import competency and composition during the first step of ascus formation.

The number of peroxisomes dramatically increases at two further developmental stages: during ascus growth (FIG. 5) and during ascospore differentiation (FIG. 7) (Berteaux-Lecellier et al. 1995). Moreover, during the first steps of ascus growth, peroxisomes display a preferential localization at the tip of the ascus. Peroxisome increase and relocalization reflect specific requirements consistent with the crucial role of peroxisomes for ascus differentiation (above). In addition, increased peroxisome activity also is required during the subsequent ascus development. Indeed defective peroxisome biogenesis resulting from elimination of either PEX5 or PEX7 produces defective spindle positioning during the second meiotic division and impaired nuclear migration during post-meiotic mitosis (Bonnet et al. 2006). Of interest these developmental processes occur after the stage where peroxisome import competency and morphology change, at the end of first meiotic division (see below).

The second increase in the number of peroxisomes is observed during ascospore differentiation and can be correlated with the fact that sporulation is defective in mutants defective for either peroxisome biogenesis (Berteaux-Lecellier et al. 1995; Bonnet et al. 2006: Peraza-Reyes et al. 2008, 2011) or for the fatty acid $\beta$-oxidation pathway (Boisnard et al. 2009). This deficiency mainly results from inhibition of ascospore cell wall melanization, which produces fragile unripe ascospores. If the $\beta$-oxidation pathway could provide precursors for melanin biosynthesis (like acetyl CoA), increased peroxisome activity could be required to 

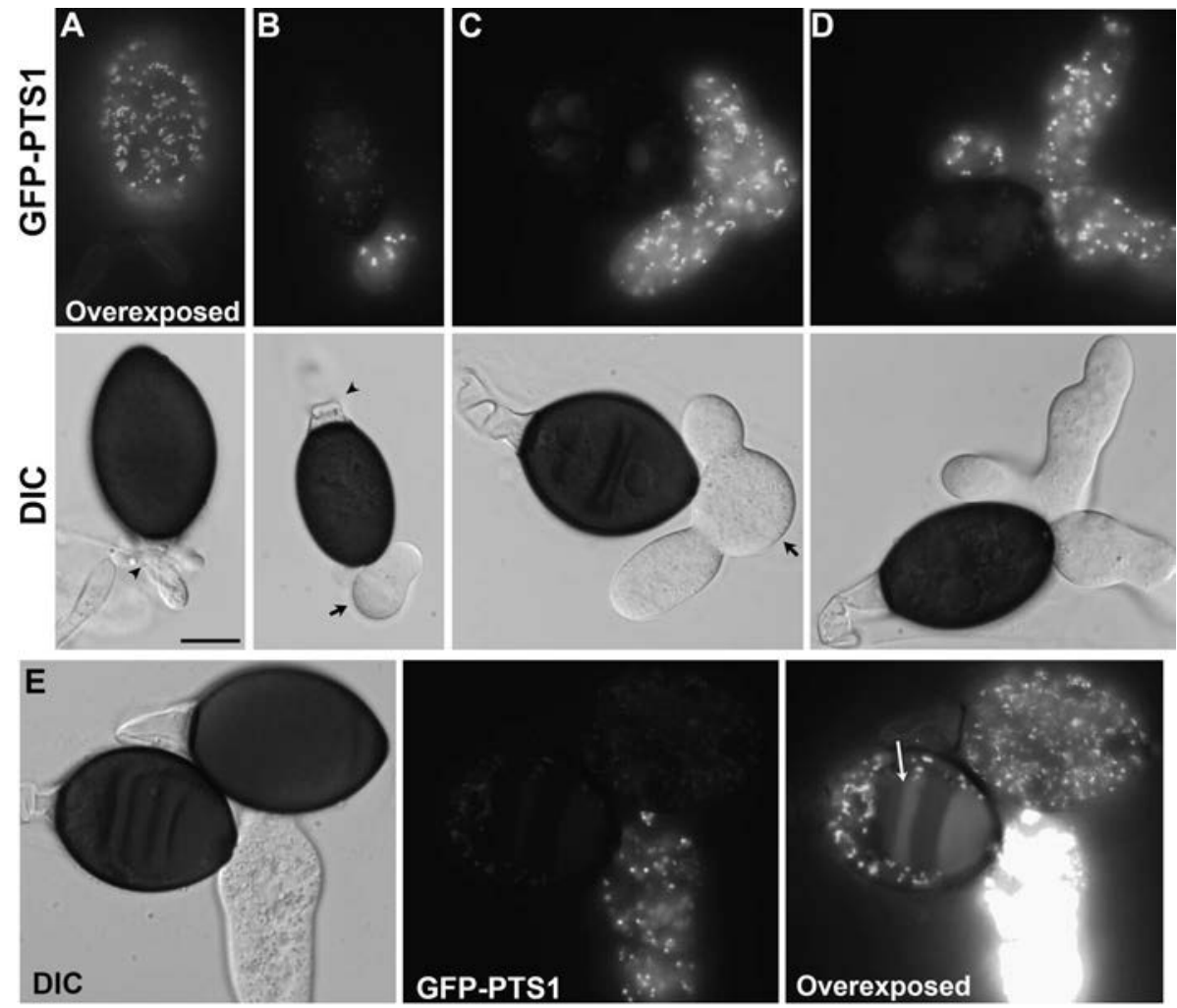

FIG. 9. Distribution of GFP-PTS1-stained peroxisomes (GFP-PTS1) during ascospore germination. DIC, corresponding differential interference contrast micrographs. A. Nongerminated ascospore with primary appendage (the remaining tail cell, arrowhead) at its base (to see the GFP fluorescence across the dark cell wall, the image was over-exposed, like in E). B. Ascospores germinate by forming a peg (arrow), which emerges at the opposite pole of the ascospore primary appendage (arrowhead). C. The germination peg grows isodiametrically and then produces hyphae, which grow away (D). E. Upon germination the protoplasm is displaced from the ascospore by a large vacuole (visible in the overexposed image, arrow), which seemingly propels most peroxisomes into the germinated cells (compare to the upper ungerminated cell). Bar $=5 \mu \mathrm{m}$.

fulfill the metabolic demand of such precursors (Boisnard et al. 2009).

We also show here that peroxisomes not only change in number but also in morphology. Predominantly spherical in dikaryotic croziers and in first meiotic division asci, they are mainly elongated (tubular) from second meiotic division until ascospore formation and then go back to a spherical form later during ascospore differentiation. Although tubular peroxisomes could reflect the need for peroxisome elongation before division and proliferation, there is no clear correlation between the stages in which peroxisomes proliferate and those harboring elongated peroxisomes. For example, while peroxisomes are predominantly spherical throughout ascus growth, those present during ascospore differentiation are mostly elongated before becoming spherical at the end of the process. In addition, elongation of peroxisomes also is observed after ascus growth (along meiotic/ postmeiotic development) without apparent increase in their number. Therefore we consider that peroxisome elongation instead could reflect a change in the redox or oxidative state of peroxisomes (or of the cell) during sexual development.

The differences in peroxisome morphology during asci and ascospore development could be produced by a differential regulation of the Pex11 family proteins, which promote membrane curvature to facilitate peroxisome elongation (Koch et al. 2004, 2010, Opalinski et al. 2011) and attract the fission machinery to the sites where peroxisomes divide (Koch and Brocard 2012).

The peroxisome morphological changes also can be correlated with the differential involvement of the peroxins of the docking/translocation machinery during sexual development. In $P$. anserina the dockingcomplex peroxins PEX14 and PEX14/17 are required for peroxisome protein import in asci after the first meiotic division and in grown ascospores but not during ascus growth or in the early stages of ascospore differentiation (Peraza-Reyes et al. 2011). Therefore the stages where peroxisome formation becomes 
dependent on Pex14 and Pex14/17 correlate with those where peroxisome morphological transitions are observed.

Our data also show that peroxisomes decrease at some steps of sexual development, revealing that peroxisomes need to be removed at specific developmental stages. Specifically the large number of peroxisomes present in grown ascospores dramatically decreases upon maturation (FIG. 8), suggesting that degradation could be required to remove the excess of peroxisomes once ascospore melanization is attained. Of interest, the remaining peroxisomes are associated in groups, suggesting a selective degradation of peroxisomes. The observed elimination of peroxisomes could be accomplished by pexophagya selective peroxisome autophagy process (Nazarko and Farré 2014) —and could be required to adjust peroxisome constitution and/or to remove damaged peroxisomes for the subsequent developmental-stage, germination. In fact, processes that compromise peroxisome integrity, such as oxidative damage, can trigger pexophagy to selectively eliminate dysfunctional organelles (Shibata et al. 2013). Moreover, as peroxisomes have recently emerged as essential organelles regulating cellular aging (Beach and Titorenko 2013), this removal process could have a role in ascospore rejuvenation before germination.

Conclusion.We previously provided evidence that distinct peroxisome protein import pathways contribute to stages of sexual development and that the functional state of the peroxisome protein translocation machinery differs at distinct developmental stages (Peraza-Reyes et al. 2011). We now show the existence of a precise modulation of peroxisome dynamics, which is correlated with these processes. Altogether our findings suggest that peroxisome function during development depends on the formation of different peroxisome populations that are associated with and are required for specific developmental stages. Our results also suggest that the constitution and function of these peroxisome populations depend on the coordinated regulation of the proteins that control peroxisome assembly and dynamics.

\section{ACKNOWLEDGMENTS}

This research was supported by grants from Universidad Nacional Autónoma de México (DGAPA-PAPIIT grant IA201815), the European Leukodystrophy Association (ELA) Research Foundation, the Agence nationale de la recherche (ANR-05-BLAN-0385-01), the Centre National de la Recherche Scientifique and the Université Paris-Sud (UMR 8621). We are much indebted to Fernando Suaste-Olmos (IFC, UNAM) for technical assistance and to Véronique Berteaux-Lecellier (CRIOBE, CNRS) and Robert Debuchy (I2BC, Université Paris-Sud) for assistance and valuable discussions.

\section{LITERATURE CITED}

Ayer A, Sanwald J, Pillay BA, Meyer AJ, Perrone GG, Dawes IW. 2013. Distinct redox regulation in subcellular compartments in response to various stress conditions in Saccharomyces cerevisiae. PLoS One 8:e65240, doi: 10.1371/journal.pone.0065240

Bartoszewska M, Opalinski L, Veenhuis M, van der Klei IJ. 2011. The significance of peroxisomes in secondary metabolite biosynthesis in filamentous fungi. Biotechnol Lett 33:1921-1931, doi:10.1007/s10529-011-0664-y

Beach A, Titorenko VI. 2013. Essential roles of peroxisomally produced and metabolized biomolecules in regulating yeast longevity. Subcell Biochem 69:153-167, doi:10. 1007/978-94-007-6889-5_9

Berteaux-Lecellier V, Picard M, Thompson-Coffe C, Zickler D, Panvier-Adoutte A, Simonet JM. 1995. A nonmammalian homolog of the PAF1 gene (Zellweger syndrome) discovered as a gene involved in caryogamy in the fungus Podospora anserina. Cell 81:1043-1051, doi:10.1016/S0092-8674(05)80009-1

Boisnard S, Espagne E, Zickler D, Bourdais A, Riquet AL, Berteaux-Lecellier V. 2009. Peroxisomal ABC transporters and beta-oxidation during the life cycle of the filamentous fungus Podospora anserina. Fungal Genet Biol 46:55-66, doi:10.1016/j.fgb.2008.10.006

Bonnet $\mathrm{C}, \longrightarrow$, Boisnard S, Bourdais A, 2006. The peroxisomal import proteins PEX2, PEX5 and PEX7 are differently involved in Podospora anserina sexual cycle. Mol Microbiol 62:157-169, doi:10. 1111/j.1365-2958.2006.05353.x

Corpas F, Barroso J, Palma J, del Río L. 2013. Peroxisomes as cell generators of reactive nitrogen species (RNS) signal molecules. In: del Río LA, ed. Peroxisomes and their key role in cellular signaling and metabolism. Springer, Netherlands. p. 283-298.

Dixit E, Boulant S, Zhang Y, Lee AS, Odendall C, Shum B, Hacohen N, Chen ZJ, Whelan SP, Fransen M , et al. et al. 2010. Peroxisomes are signaling platforms for antiviral innate immunity. Cell 141:668-681, doi:10.1016/ j.cell.2010.04.018

Egan MJ, Tan K, Reck-Peterson SL. 2012. Lis1 is an initiation factor for dynein-driven organelle transport. J Cell Biol 197:971-982, doi:10.1083/jcb.201112101

Freitag J, Ast J, Bolker M. 2012. Cryptic peroxisomal targeting via alternative splicing and stop codon read-through in fungi. Nature 485:522-525, doi:10.1038/nature11051

, - Linne U, Stehlik T, Martorana D, Bolker M, Sandrock B. 2014. Peroxisomes contribute to biosynthesis of extracellular glycolipids in fungi. Mol Microbiol 93:24-36, doi:10.1111/mmi.12642

Gabaldon T. 2010. Peroxisome diversity and evolution. Philos Trans R Soc Lond B Biol Sci 365:765-73, doi:10.1098/ rstb.2009.0240

Grundlinger M, Yasmin S, Lechner BE, Geley S, Schrettl M, Hynes M, Haas H. 2013. Fungal siderophore biosynthesis is partially localized in peroxisomes. Mol Microbiol 88:862-75, doi:10.1111/mmi.12225

Hickey PC, Jacobson D, Read ND, Glass NL. 2002. Live-cell imaging of vegetative hyphal fusion in Neurospora crassa. 
Fungal Genet Biol 37:109-119, doi:10.1016/S1087-1845 (02) 00035-X

Ivashchenko O, van Veldhoven PP, Brees C, Ho YS, Terlecky SR, Fransen M. 2011. Intraperoxisomal redox balance in mammalian cells: oxidative stress and interorganellar cross talk. Mol Biol Cell 22:1440-1451, doi:10.1091/ mbc.E10-11-0919

Jedd G. 2011. Fungal evo-devo: organelles and multicellular complexity. Trends Cell Biol 21:12-19, doi:10.1016/ j.tcb.2010.09.001

Kiel JA, Veenhuis M, van der Klei IJ. 2006. PEX genes in fungal genomes: common, rare or redundant. Traffic 7:1291-1303, doi:10.1111/j.1600-0854.2006.00479.x

Kim PK, Hettema EH. 2015. Multiple pathways for protein transport to peroxisomes. J Mol Biol 427:1176-1190, doi:10.1016/j.jmb.2015.02.005

Koch A, Schneider G, Luers GH, Schrader M. 2004. Peroxisome elongation and constriction but not fission can occur independently of dynamin-like protein 1 . J Cell Sci 117:3995-4006, doi:10.1242/jcs.01268

Koch J, Brocard C. 2012. PEX11 proteins attract Mff and human Fis1 to coordinate peroxisomal fission. J Cell Sci 125:3813-3826, doi:10.1242/jcs.102178

— , Pranjic K, Huber A, Ellinger A, Hartig A, Kragler F, Brocard C. 2010. PEX11 family members are membrane elongation factors that coordinate peroxisome proliferation and maintenance. J Cell Sci 123:3389-3400, doi:10. 1242/jcs.064907

Kunze M, Pracharoenwattana I, Smith SM, Hartig A. 2006. A central role for the peroxisomal membrane in glyoxylate cycle function. Biochim Biophys Acta 1763: 1441-1452, doi:10.1016/j.bbamcr.2006.09.009

León J. 2013. Role of plant peroxisomes in the production of jasmonic acid-based signals. In: del Río LA, ed. Peroxisomes and their key role in cellular signaling and metabolism. Springer, Netherlands. p 299-313.

Lodhi IJ, Semenkovich CF. 2014. Peroxisomes: a nexus for lipid metabolism and cellular signaling. Cell Metab 19:380-392, doi:10.1016/j.cmet.2014.01.002

Lopez-Huertas E, Charlton WL, Johnson B, Graham IA, Baker A. 2000. Stress induces peroxisome biogenesis genes. EMBO J 19:6770-6777, doi:10.1093/emboj/19. 24.6770

Managadze D, Wurtz C, Wiese S, Schneider M, Girzalsky W, Meyer HE, Erdmann R, Warscheid B, Rottensteiner H. 2010. Identification of PEX33, a novel component of the peroxisomal docking complex in the filamentous fungus Neurospora crassa. Eur J Cell Biol 89:955-964, doi:10.1016/j.ejcb.2010.07.003

Maruyama J, Kitamoto K. 2013. Expanding functional repertoires of fungal peroxisomes: contribution to growth and survival processes. Front Physiol 4:177, doi:10. 3389/fphys.2013.00177

Meinecke M, Cizmowski C, Schliebs W, Kruger V, Beck S, Wagner R, Erdmann R. 2010. The peroxisomal importomer constitutes a large and highly dynamic pore. Nat Cell Biol 12:273-277, doi:10.1038/ncb2027

Nazarko T, Farré J-C. 2014. Molecular machines involved in pexophagy. In: Brocard C, Hartig A, eds. Molecular machines involved in peroxisome biogenesis and maintenance. Springer, Vienna. p 481-506.

Nordgren M, Fransen M. 2013. Peroxisomal metabolism and oxidative stress. Biochimie 98:56-62, doi:10.1016/ j.biochi.2013.07.026

Opalinski L, Kiel JA, Homan TG, Veenhuis M, van der Klei IJ. 2010. Penicillium chrysogenum Pex14/17p-a novel component of the peroxisomal membrane that is important for penicillin production. Febs J 277:3203-3218, doi:10. $1111 /$ j.1742-4658.2010.07726

—, Williams C, — - - 2011. Membrane curvature during peroxisome fission requires Pex11. EMBO J 30:5-16, doi:10.1038/emboj.2010.299

Peraza-Reyes L, Arnaise S, Zickler D, Coppin E, Debuchy R, Berteaux-Lecellier V. 2011. The importomer peroxins are differentially required for peroxisome assembly and meiotic development in Podospora anserina: insights into a new peroxisome import pathway. Mol Microbiol 82:365-377, doi:10.1111/j.1365-2958.2011.07816.x

, Berteaux-Lecellier V. 2013. Peroxisomes and sexual development in fungi. Front Physiol 4:244, doi:10. 3389/fphys.2013.00244

—, Zickler D, Berteaux-Lecellier V. 2008. The peroxisome RING-finger complex is required for meiocyte formation in the fungus Podospora anserina. Traffic 9: 1998-2009, doi:10.1111/j.1600-0854.2008.00812.x

Platta HW, Hagen S, Reidick C, Erdmann R. 2014. The peroxisomal receptor dislocation pathway: to the exportomer and beyond. Biochimie 98:16-28, doi:10.1016/ j.biochi.2013.12.009

Raju NB, Perkins DD. 1994. Diverse programs of ascus development in pseudohomothallic species of Neurospora, Gelasinospora and Podospora. Dev Genet 15: 104-118, doi:10.1002/dvg.1020150111

Rizet G, Engelmann C. 1949. Contribution à l'étude génétique d'un ascomycète tétrasporé : Podospora anserina. Rehm Rev Cytol Biol Veg 11:201-304.

Ruprich-Robert G, Berteaux-Lecellier V, Zickler D, PanvierAdoutte A, Picard M. 2002. Identification of six loci in which mutations partially restore peroxisome biogenesis and/or alleviate the metabolic defect of pex2 mutants in podospora. Genetics 161:1089-99.

Sandalio LM, Rodríguez-Serrano M, Romero-Puertas MC, del Río LA. 2013. Role of peroxisomes as a source of reactive oxygen species (ROS) signaling molecules. In: del Río LA, ed. Peroxisomes and their key role in cellular signaling and metabolism. Springer, Netherlands. p 231-255.

Schrader M, Bonekamp NA, Islinger M. 2012. Fission and proliferation of peroxisomes. Biochim Biophys Acta 1822:1343-1357, doi:10.1016/j.bbadis.2011.12.014

— Wodopia R, Fahimi HD. 1999. Induction of tubular peroxisomes by UV irradiation and reactive oxygen species in HepG2 cells. J Histochem Cytochem 47: 1141-1148, doi:10.1177/002215549904700906

Shibata M, Oikawa K, Yoshimoto K, Kondo M, Mano S, Yamada K, Hayashi M, Sakamoto W, Ohsumi Y, Nishimura M. 2013. Highly oxidized peroxisomes are selectively degraded via autophagy in Arabidopsis. Plant Cell 25:4967-4983, doi:10.1105/tpc.113.116947 
Sinclair AM, Trobacher CP, Mathur N, Greenwood JS, Mathur J. 2009. Peroxule extension over ER-defined paths constitutes a rapid subcellular response to hydroxyl stress. Plant J 59:231-242, doi:10.1111/j.1365-313X. 2009.03863.x

Spiess G, Zolman B. 2013. Peroxisomes as a Source of Auxin Signaling Molecules. In: del Río LA, ed. Peroxisomes and their key role in cellular signaling and metabolism. Springer, Netherlands. p. 257-281.

Stehlik T, Sandrock B, Ast J, Freitag J. 2014. Fungal peroxisomes as biosynthetic organelles. Curr Opin Microbiol 22:8-14, doi:10.1016/j.mib.2014.09.011

Strijbis K, van den Burg J, Visser WF, van den Berg M, Distel B. 2012. Alternative splicing directs dual localization of Candida albicans 6-phosphogluconate dehydrogenase to cytosol and peroxisomes. FEMS Yeast Res 12:61-68, doi:10.1111/j.1365-313X.2009.03863.x

Tanabe Y, Maruyama J, Yamaoka S, Yahagi D, Matsuo I, Tsutsumi N, Kitamoto K. 2011. Peroxisomes are involved in biotin biosynthesis in Aspergillus and Arabidopsis. J Biol Chem 286:30455-30461, doi:10.1074/jbc.M111.247338

Thompson-Coffe C, Zickler D. 1994. How the cytoskeleton recognizes and sorts nuclei of opposite mating type during the sexual cycle in filamentous ascomycetes. Dev Biol 165:257-271, doi:10.1006/dbio.1994.1251

Valenciano S, Lucas JR, Pedregosa A, Monistrol IF, Laborda F. 1996. Induction of beta-oxidation enzymes and microbody proliferation in Aspergillus nidulans. Arch Microbiol 166:336-341, doi:10.1007/s002030050392

van der Klei IJ, Yurimoto H, Sakai Y, Veenhuis M. 2006. The significance of peroxisomes in methanol metabolism in methylotrophic yeast. Biochim Biophys Acta 1763:1453-1462, doi:10.1016/j.bbamcr.2006.07.016

Veenhuis M, Mateblowski M, Kunau WH, Harder W. 1987. Proliferation of microbodies in Saccharomyces cerevisiae. Yeast 3:77-84, doi:10.1002/yea.320030204

Wanders RJ, Waterham HR. 2006. Biochemistry of mammalian peroxisomes revisited. Annu Rev Biochem 75:295-332, doi:10.1146/annurev.biochem.74.082803. 133329

Zhang J, Kim J, Alexander A, Cai S, Tripathi DN, Dere R, Tee AR, Tait-Mulder J, Di Nardo A, Han JM. 2013. A tuberous sclerosis complex signalling node at the peroxisome regulates mTORC1 and autophagy in response to ROS. Nat Cell Biol 15:1186-1196, doi:10. $1038 /$ ncb2822 